\title{
ETHOLOGY
}

\section{Evaluating the quality of the Mexican fruit-fly, Anastrepha ludens, as host for the parasitoid Melittobia digitata}

\author{
J.M. González, ${ }^{1}$ M. Aluja, ${ }^{2}$ A. Cusumano, ${ }^{3}$ S. Colazza, ${ }^{3}$ S.B. Vinson ${ }^{4}$ \\ 'Department of Plant Science, California State University, Fresno, CA, USA; 'Instituto de Ecología, \\ Xalapa, Veracruz, México; ${ }^{3}$ Dipartimento di Scienze Agrarie e Forestali, Università di Palermo, \\ Italy; ${ }^{4}$ Department of Entomology, Texas A\&M University, College station, TX, USA
}

\begin{abstract}
We investigated the presence of Melittobia digitata (Hymenoptera: Eulophidae) and its associations with its natural hosts in Veracruz, Mexico. The parasitoid was confirmed to be present and found to
\end{abstract}

Correspondence: Antonino Cusumano, Dipartimento di Scienze Agrarie e Forestali, Università degli Studi di Palermo, viale delle Scienze, 90128, Palermo, Italy.

E-mail: antonino.cusumano@unipa.it

Key words: biological pest control, pupal parasitoids, Eulophidae, Tephritidae.

Acknowledgements: we gratefully acknowledge Jovita Martínez Tlapa, Andrea Birke, Emilio Acosta, Carlo Sormani, Juan Rull, Larissa Guillén, Rafael Ortega Casas, (all from Instituto de Ecología, A.C. [INECOL], Xalapa, Veracruz, México) for technical and logistic support. JMG especially thanks all personnel and students of the Applied Entomology Unit of INECOL for their help, kindness and attentions while in México. This work was funded through grants to SBV, MA and JMG by the Texas A \& M University - Consejo Nacional de Ciencia y Tecnología (TAMU-CONACyT) collaborative Research Grant Program (Project No. 100108) and to MA from the Mexican Campaña Nacional Contra Moscas de la Fruta (Convenio IICA-DGSV-INECOL). MA also acknowledges financial support from the INECOL and thanks CONACyT Sabbatical Year Fellowship (Ref. 79449), TAMU-CONACYT Program (Improving Ecologically Based Pest management of Anastrepha Fruit Flies; to Robert Wharton and MA) and CONACyT Grant 46846-Q. We are greatly indebted to Hugh Conway (USDA) for providing us with A. ludens for our tests in the US, and to the USDA personnel in charge of permits which allowed us to transport the insects. Our deepest appreciation goes to Robert W. Matthews (University of Georgia) for enlightening comments and corrections that improved the original manuscript.

Contributions: JMG, MA, SBV, conceived and designed the experiments; JMG, MA, performed the experiments; AC, SC, analyzed the data; JMG, MA, $\mathrm{AC}, \mathrm{SC}, \mathrm{SBV}$, wrote the paper.

Received for publication: 30 April 2013.

Revision received: 1 July 2013.

Accepted for publication: 10 July 2013.

This work is licensed under a Creative Commons Attribution NonCommercial 3.0 License (CC BY-NC 3.0).

(C) Copyright J.M. González et al., 2013

Licensee PAGEPress, Italy

Entomologia 2013; 1:e5

doi:10.4081/entomologia.2013.e5 attack prepupae of Trypoxylon and Sceliphron (Hymenoptera: Crabronidae and Sphecidae, respectively) mud daubers as well as pupae of the Mexican fruit fly Anastrepha ludens (Diptera: Tephritidae). Since A. ludens is a very important pest of citrus and mango in Mexico and Central America, we evaluated, in laboratory experiments, the quality of $A$. ludens as host of $M$. digitata comparing the development of the parasitoid in another unrelated fly species (Sarcophaga [Neobellieria] bullata) (Diptera: Sarcophagidae) and in mud dauber wasps (Trypoxylon sp. and Sceliphron sp.). The Mexican fruit fly appears to be a good-quality host for $M$. digitata, and the results are discussed in the context of their possible interest as a natural enemy of $A$. ludens.

\section{Introduction}

Melittobia is a cosmopolitan genus of parasitoid wasps with 12 species (Matthews \& González, 2008; Matthews et al., 2009; Tanner et al., 2011). Wasps of this genus are small (1.0-1.5 mm) ectoparasitic arrhenotokous idiobionts that develop gregariously on their hosts (Matthews et al., 2009). Melittobia wasps are sexually dimorphic, and females are polymorphic (short winged and long winged) (Cônsoli \& Vinson, 2002a,b; González \& Matthews, 2005, 2008; Matthews et al., 2009). Long-winged females, also called macropterous females, are the dispersal stage, while some non-dispersing short-winged females, also called brachypterous females, may be produced in some large hosts (Cônsoli \& Vinson, 2004).

In North America seven Melittobia species have been reported attacking a wide range of hosts but they are mainly associated with mud dauber wasp species (Matthews et al., 2009), while in Mexico only two of them, belonging to different species-groups are known: Melittobia australica Girault and M. digitata Dahms (González et al., 2008, 2010; Tanner et al., 2011). The first species was found attacking wasps (Hymenoptera) such as Euodynerus hidalgo vierecki (Cameron) (Vespidae), Chrysis wasbaueri Bohart (Chrysididae) and Sceliphron spp. (Sphecidae), while the latter has been found attacking Trypoxylon mexicanum (Saussure) (Crabronidae), but was unexpectedly recorded from pupae of the pestiferous tephritid fly Anastrepha ludens Loew (Tephritidae) also known as the Mexican fruit fly (Copeland et al., 2008; González et al., 2008, 2010). Anastrepha ludens is a very important pest of citrus and mango in Mexico and Central America (Hernández-Ortiz, 1992; Aluja, 1994; Aluja et al., 1996, 2009; Birke et al., 2006). In the USA it is considered a pest of quarantine importance, with management/eradication programs in place in Texas and California (Mangan et al., 1997; Thomas, 2003; Thomas, et al. 2008; 
Aluja \& Mangan, 2008). Biological control of tephritid fruit flies, including $A$. ludens, largely relies on larval/egg-prepupal braconid parasitoids (Purcell, 1998; Ovruski et al., 2000), but under restricted conditions, a pupal parasitoid could be used in combination with larval parasitoids, because pests escaping larval parasitism may be attacked during the pupal stage, thus reducing the overall pest population (López et al., 1999).

The use of pupal parasitoids can be recommended especially when tephritid fruit flies infest large fruits, such as citrus and mangoes, because it has been shown that there is a negative correlation between fruit size and percentage of parasitism by braconid parasitoids (Sivinski, 1991; López et al., 1999; Cancino et al., 2009). Excluding $M$. digitata, only a few pupal parasitoids associated with tephritid fruit flies have been reported in Mexico, including Coptera haywardi (Oglobin) (Diapriidae), Pachycrepoideus vindemmiae (Rondani) (Pteromalidae), and Eurytoma sivinskii Gates and Grisell (Eurytomidae) (Mena-Correa et al., 2010 and references within). Melittobia digitata is a species only known from North America; in the continental USA it has been reported attacking various Diptera and Hymenoptera at several locations (Dahms, 1984; La Salle, 1993; Matthews et al., 2009). It is one of the best studied species in the genus and is also widely used in science curricula (Matthews et al., 2009).

The goals of this study were to i) investigate how common $M$. digita$t a$ is as a parasitoid of mud dauber wasps in the area of Veracruz, Mexico; ii) inspect field collections of $A$. ludens pupae stored at the Instituto de Ecología, A.C. (INECOL) to confirm the presence of $M$. digitata as a natural parasitoid of the Mexican fruit fly; iii) evaluate the quality of $A$. ludens as a host of $M$. digitata and to compare its development with another totally unrelated host fly species [Sarcophaga (Neobellieria) bullata Parker] (Sarcophagidae) which is commercially used to rear M. digitata wasps (Matthews et al., 1996), as well as mud dauber wasps within the Crabronidae and Sphecidae (Trypoxylon and Sceliphron species, respectively, both Hymenoptera). In addition to the importance of these basic ecological studies, this information could be relevant when trying to identify new biological control agents and their potential risks to the local entomofauna (Simberloff \& Stiling, 1996).

\section{Materials and Methods}

\section{Field-survey in Veracruz, Mexico}

Several sites were visited along the roads of Xalapa and the surrounding areas of north central Veracruz, Mexico. Locations visited were all north of the Cordoba-Veracruz road, east of the Perote - Xalapa - Coatepec axis, up to Papantla de Olarte and along the coast from La Guadalupe to Veracruz. Surveys were carried out in May and June, 2008. Their main purpose was to collect mud dauber wasps (i.e., Sceliphron, Trypoxylon) to look for unparasitized host larvae and/or pre-pupae as well as to corroborate the presence of Melittobia wasps in natural situations in the field. During the two months before the MayJune trips, trap nests made of hollow bamboo sticks (hole sizes ranging from 5 to $10 \mathrm{~mm}$ diameter; $150 \mathrm{~mm}$ long) were also placed in various sites in Xalapa and its vicinity. The collected mud dauber wasp nests and the bamboo trap nests were transferred in the Applied Entomology Unit laboratories at Instituto de Ecología, A.C. (INECOL) (Xalapa, Veracruz, Mexico) and dissected to look for Melittobia wasps.

\section{Insect collections kept at INECOL, Veracruz, Mexico}

About 100 Mexican fruit fly pupae samples collected from 1997 mainly in Xalapa, but also in Los Tuxlas, Veracruz, Soconusco, Chiapas, and an unknown locality in Michoacán, and gathered over about 10 years in the INECOL laboratories were inspected for the presence of Melittobia spp.
Mexican fruit fly specimens were stored singly in vials in alcohol (70\%). The insects found in storage were originally collected from field infested A. ludens pupae brought to the Fruit Flies laboratory at INECOL.

\section{Insects used in bioassays}

\section{Parasitoids}

Melittobia digitata experimental cultures were established with female wasps obtained from stock cultures at INECOL from field-collected $A$. ludens pupae. The $M$. digitata culture was kept in an incubator at $24 \pm 2{ }^{\circ} \mathrm{C}$ and $70 \% \mathrm{RH}$ in total darkness. Only macropterous (long wing) females less than 5 days old and inexperienced from oviposition were used in experiments. Because of their age, and because they were taken directly from cultures before use in the bioassays, parasitoids were assumed to be mated.

\section{Hosts}

Anastrepha ludens. Mexican fruit fly pupae $<24$ hours old were obtained from the rearing rooms at the Applied Entomology Unit laboratories (INECOL) in Xalapa, Veracruz, (for experiments in Mexico), and the USDA-APHIS-PPQ-CPHST laboratories, in Mission, Texas (for experiments in the United States). Upon receiving the pupae, they were immediately introduced individually with a female of $M$. digitata, in a vial, to be parasitized.

Trypoxylon sp. and Sceliphron sp. mud dauber prepupae, obtained from field collections (in Veracruz, Mexico), were kept in a refrigerator $\left(<12^{\circ} \mathrm{C}\right)$ to maintain the prepupae in diapause (to be eventually used as hosts). Before use in these bioassays, each cocoon was gently broken at the subtruncate cap (Cross et al., 1975) opening a small orifice to verify that the prepupa was healthy and not parasitized.

Sarcophaga (Neobelleria) bullata. A factitious host, S. bullata pupae are often used in commercial production of $M$. digitata (Matthews et al., 2009) and were obtained from a commercial source (Carolina Biological Supply, Burlington, NC, USA).

\section{Host-quality bioassays}

Two hundred fresh pupae of $A$. ludens ( $<4$ day-old; weight: $0.021 \pm 0.004 \mathrm{~g}(\mathrm{mean} \mathrm{SE})$ were individually placed in 2-dram glass vials. Subsequently, $M$. digitata females were transferred individually from the INECOL cultures into the vials containing one A. ludens pupa each. Sceliphron sp. prepupae $\left(\mathrm{n}=15\right.$; weight: $0.199_{ \pm 0.013 \mathrm{~g}) \text { and }}$ Trypoxylon sp. prepupae $(\mathrm{n}=15$; weight: $0.300 \pm 0.033 \mathrm{~g})$ were also placed in 2 dram vials ( 1 prepupa/vial) into which one mated $M$. digitata female was also introduced. Even though a larger geographical area in Veracruz, Mexico was covered in an effort to collect mud dauber wasp nests, we were only able to collect a limited number of prepupae of Trypoxylon sp. and Sceliphron sp. from the field. That is the reason why we used only 15 hosts of each of these species in this investigation. All vials were plugged with raw cotton to preclude parasitoid females from escaping and were placed inside an incubator kept at a temperature of $24 \pm 2^{\circ} \mathrm{C}$ and $60 \% \mathrm{RH}$.

Development of $M$. digitata was studied for each of the three types of hosts. Emerging parasitoids were killed by freezing $\left(-18^{\circ} \mathrm{C}\right)$ on the day of their emergence and preserved in alcohol (70\%). For each host species, the fitness traits used to evaluate host-quality for $M$. digitata were (i) relative clutch size (number of emerged wasps/host weight), (ii) developmental time (recorded daily for both macropteorus $\circ \rightarrow$ and $\lambda \hat{\gamma}$ ), and (iii) sex ratio (\% of emerged males). The relative clutch size was considered in order to make comparisons among hosts of different weight. The adult body size was not taken into account in these experiments because in several species of Melittobia, including $M$. digitata, females generally tend to adjust clutch size but not body size when developing on different hosts (González \& Matthews, 2002; González et al., 2004a,b; Matthews et al., 2009). 
For comparative purposes, the development of the same strain of $M$. digitata was also studied in $S$. (Neobellieria) bullata and in A. ludens in laboratories at Texas A\&M University, measuring the same fitness traits as described above. One hundred pupae of $A$. ludens $(<4$ days old; weight: $0.021 \pm 0.001 \mathrm{~g}$ ) were each placed inside 2 -dram glass vials with a $M$. digitata female. The same was done with pupae of $S$. bullata $(\mathrm{n}=100 ;<5$ days old; $0.133 \pm 0.015 \mathrm{~g}$ ). These cultures were maintained under alternating light and dark cycles of $12 \mathrm{~h}$ each at $25 \pm 2{ }^{\circ} \mathrm{C}$ and $70 \%$ $\mathrm{RH}$ in the rearing chambers of the Entomology Research laboratory of the Department of Entomology at Texas A\&M University.

\section{Statistical analysis}

The effects of host type on relative clutch size, developmental time, and sex ratio were compared, within each locality, with the KruskalWallis ANOVA followed by the Dunn's test for post-hoc comparisons (Siegel \& Castellan, 1988; Zar, 1999). All statistical analyses were processed using STATISTICA7 software (StatSoft, 2001).

\section{Results}

\section{Field-survey in Veracruz, Mexico}

Live $M$. digitata wasps were only found and retrieved from three localities: (1) Emiliano Zapata, Veracruz (N 19² 26.7' W 96 ${ }^{\circ} 46.9^{\prime}, 890$ m, VI-2008) inside a Trypoxylon wasp nest; (2) Colorado, Santa Monica, Veracruz, Finca San Marco (N 20 4.9' W 96 55.8', 49 m, VI-2008) inside a cocoon of Sceliphron sp. that was inside a cell of a Trypoxylon sp. nest; and (3a) INECOL, Col. El Haya, Xalapa, Veracruz, VI, 2009, bamboo trap nest used by Trypoxylon sp.; (3b) INECOL, Col. El Haya, Xalapa, Veracruz, 29-VI, 2009, Trypoxylon sp. nest; (3c) INECOL, Col. El Haya, Xalapa, Veracruz, 29-VI, 2009, Trypoxylon sp. nest.

\section{Insect collections kept at INECOL, Veracruz, Mexico}

A total of 7 vials in storage were found containing a variable number of old A. ludens pupae and pupal remains (in some cases hosts were broken in pieces and we were unable to know exactly how many pupae were originally placed in the vials) in the Fruit Flies laboratory at INECOL. They were originally collected between January 1997 and March 2005, and together with these old pupae numerous dead speci-

\section{Clutch size}

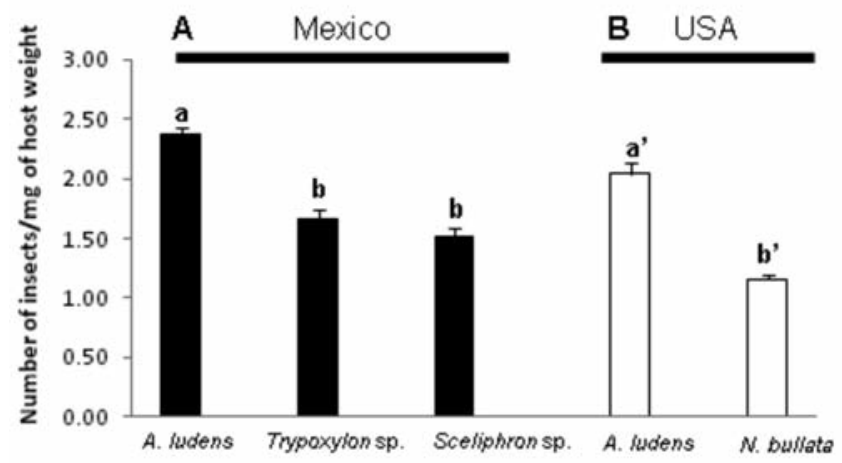

Figure 1. Values (mean $\pm \mathrm{SE}$ ) of clutch size of $M$. digitata when developing on different host types at two localities. A) Mexico=black bars; B) USA=white bars. Different letters above bars indicate statistical significant differences within the same locality (Kruskal-Wallis ANOVA, Dunn's test, $\mathbf{P}<0.05$ ). mens of $M$. digitata were also found: [vial 1 (1997): 20 우, Michoacán; vial 2 (2003): $5 \hat{\jmath}$; >300 우, Los Tuxlas, Veracruz; vial 3 (2003): 15 $\circ ㅇ$, Los Tuxtlas, Veracruz; vial 4 (2005): $25 \circ \circ$, Soconusco, Chiapas;

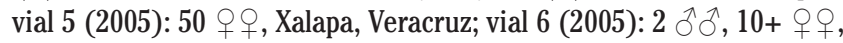
Los Tuxlas, Veracruz; vial 7 (2005): 6 우, Xalapa, Veracruz)].

\section{Host-quality bioassays}

\section{Mexico}

Almost all the exposed hosts yielded $M$. digitata adults; from $A$. ludens, from Trypoxylon sp., and from Sceliphron sp., 99.5, 100 and 100\% of the hosts produced parasitoids, respectively. In terms of relative clutch size, significantly more wasps emerged from $A$. ludens $(2.37 \pm 0.06 \mathrm{mg}$ of host weight) compared with Trypoxylon sp. (1.66 $\pm 0.07 \mathrm{mg}$ of host weight) and Sceliphron sp. $(1.51 \pm 0.07 \mathrm{mg}$ of host weight) $[\mathrm{H}(2, \mathrm{n}=229)=29.28$, $\mathrm{P}<0.001]$ (Figure 1A). The developmental time (days) of macropterous M. digitata females was not significantly different between hosts [H (2, $\mathrm{n}=70)=1.26, \mathrm{P}=0.5317$ ] (Figure $2 \mathrm{~A}$ ), and values were very similar $(A$. ludens $=23.58 \pm 0.22 ;$ Trypoxylon $\mathrm{sp} .=23.33 \pm 0.32 ;$ Sceliphron $\mathrm{sp} .=23.00$ $\pm 0.49)$. However males required significantly more time when developing on $A$. ludens $(19.50 \pm 0.13)$ compared with Trypoxylon sp. $(17.40 \pm 0.16)$ or with Sceliphron sp. $(17.33 \pm 0.13)$ [H $(2, n=68)=51.86$, $\mathrm{P}<0.001$ ] (Figure 2A). A significant effect of the host species was found
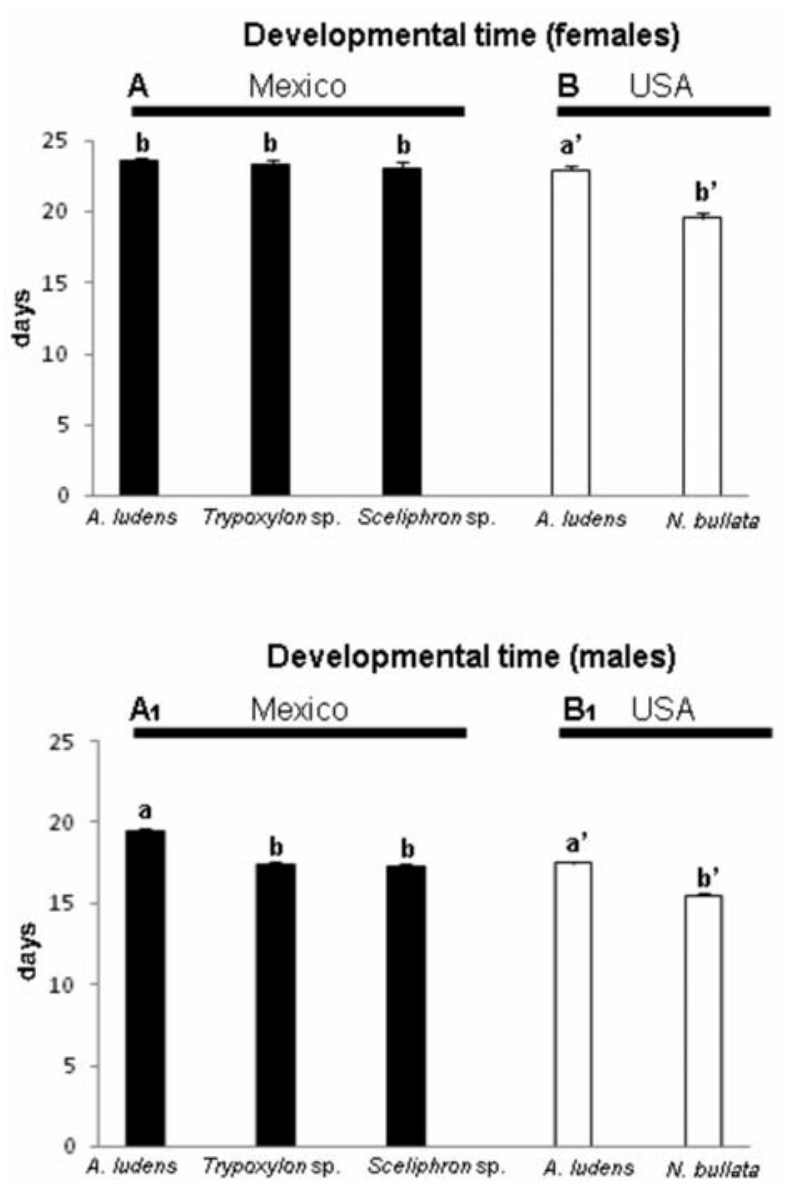

Figure 2. Values (mean \pm SE) of developmental time of $M$. digitata macropterous females (A) and males $(B)$ when developing on different host types at two localities (Mexico=black bars; USA=white bars). Different letters above bars indicate statistical significant differences within the same locality (Kruskal-Wallis ANOVA, Dunn's test, $\mathrm{P}<0.05)$. 
on sex ratio of $M$. digitata $[\mathrm{H}(2, \mathrm{n}=229)=14.81, \mathrm{P}<0.001]$ (Figure $3 \mathrm{~A})$. In fact, the proportion of males was higher on A. ludens $(3.26 \pm 0.15 \%)$ compared with Sceliphron sp. $(1.71 \pm 0.09 \%)$ whereas an intermediate value was found for Trypoxylon sp. $(2.61 \pm 0.08 \%)$. Brachypterous females were found when $M$. digitata exploited both mud dauber wasp species but not on the Mexican fruit fly (Table 1).

\section{USA}

Melittobia digitata adults emerged from all the exposed A. ludens hosts whereas $84.0 \%$ of the $N$. bullata hosts yielded parasitoids. In terms of relative cutch size, significantly more $M$. digitata wasps emerged from $A$. ludens $(2.04 \pm 0.09)$ vs. $N$. bullata $(1.16 \pm 0.03)$ [ $\mathrm{H}(1$, $\mathrm{n}=184$ ) $=46.21, \mathrm{P}<0.001]$ (Figure 1B). The developmental time (days) of macropterous $M$. digitata females was significantly higher on $A$. ludens $(22.95 \pm 0.21)$ compared with $N$. bullata $(19.55 \pm 0.31)$ [H (1, $\mathrm{n}=62)=36.09, \mathrm{P}<0.001$ ] (Figure 2B). Similarly, the developmental time of males was significantly higher on A. ludens $(17.46 \pm 0.10)$ compared with $N$. bullata $(15.50 \pm 0.15)$ [ $\mathrm{H}(1, \mathrm{n}=55)=36.61, \mathrm{P}<0.001]$ (Figure 2B). Sex ratio was significantly higher when $M$. digitata developed on $A$. ludens $(4.03 \pm 0.23 \%)$ compared to when it developed on $S$. bullata $(2.28 \pm 0.12 \%) \quad[\mathrm{H}(1, \mathrm{n}=184)=44.58, \mathrm{P}<0.001]$ (Figure 3B). Brachypterous females were found when $M$. digitata developed on $N$. bullata but not when A. ludens was used as host (Table 1).

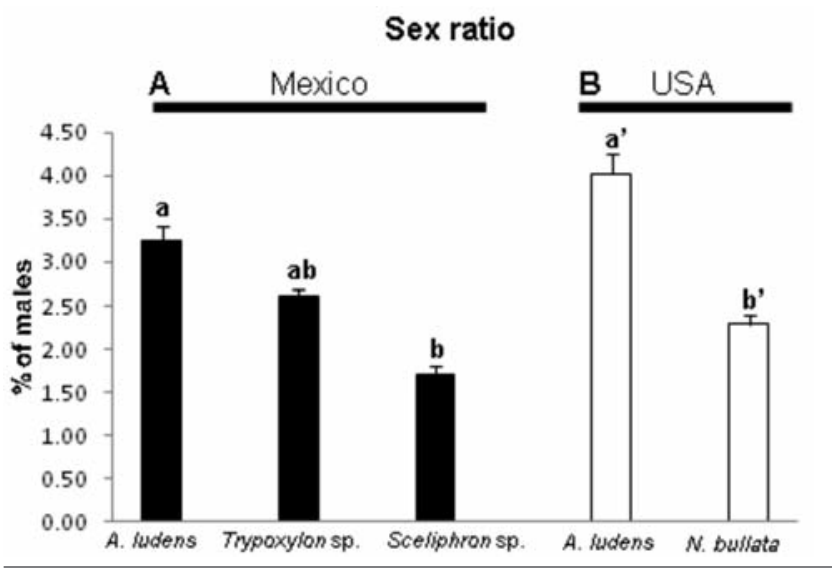

Figure 3. Values (percentage $\pm S E$ ) of sex ratio of $M$. digitata when developing on different host types at two localities. A) Mexico=black bars; B) USA=white bars. Different letters above bars indicate statistical significant differences within the same locality (Kruskal-Wallis ANOVA, Dunn's test, $P<0.05$ ).

\section{Discussion}

Our data confirmed that $M$. digitata is present in Mexico as a natural parasitoid of mud dauber wasps of the genus Trypoxylon and Sceliphron. Furthermore we also confirmed the natural host-parasitoid association $M$. digitata with $A$. ludens from at least 1997 (Copeland et al., 2008; González et al., 2008). Considering that pupae of the Mexican fruit fly have been found parasitized by $M$. digitata in at least three locations in Mexico (Los Tuxtlas, Veracruz; Soconusco, Chiapas; and Michoacán), it seems unlikely that parasitism could be coincidental even if such possibility cannot be completely excluded (González et al., $2008 ; 2010)$. It is thus interesting in trying to understand why this hostparasitoid association had been found only recently. A possible explanation could be due to the habit of fruit fly larvae of pupating in the soil at depths of $\sim 5 \mathrm{~cm}$ from the surface (Hodgson et al., 1998), making it difficult to clearly assess the parasitoid complex associated with $A$. ludens pupae, especially when levels of parasitism are low.

Under laboratory conditions, $A$. ludens appears to be a good-quality host for $M$. digitata when comparing offspring fitness traits from different host species. In fact, our data on relative clutch size revealed that $M$. digitata produced significantly more offspring per $\mathrm{mg}$ of host resources when developing on $A$. ludens than on mud dauber wasps (Trypoxylon sp. and Sceliphron sp.) or S. bullata. Furthermore, in terms of developmental time, there are also no fitness costs for macropterous females associated with $A$. ludens compared with the other natural hosts tested in this study. However developmental time of males was significantly higher when developing on A. ludens and the proportion of males was significantly higher when $M$. digitata developed on $A$. ludens, compared with Sceliphron sp. and $S$. bullata, even though the sex ratio is still highly female biased ( $>95 \%$ females are produced). Our results suggest that $A$. ludens pupae are hosts of good suitability for rearing $M$. digitata but further data that take into account nutritional differences among host species could be useful in order to have a more complete view about the quality of $A$. ludens as host for $M$. digitata.

The individuals of $M$. digitata collected from Mexico were able to produce the brachypterous female morph only with some of the tested hosts, but none were produced on A. ludens pupae and rarely did a Melittobia female produce brachypterous females when $S$. bullata pupae are used as hosts. The mechanism controlling production of both female morphs in Melittobia wasps is poorly known, but it seems to be related with the host size (Cônsoli \& Vinson, 2004; Matthews et al., 2009). In order to consume all the host resources of large size hosts like Trypoxylon sp. and Sceliphron sp. the ovipositing macropterous female produce brachypterous females, which do not disperse, but lay eggs on the host from which they have emerged: as a result, two distinct adult clutches develop from the same host (Matthews et al., 2009). In small

Table 1. Offspring (mean \pm SE) produced by Melittobia digitata from Mexico, on various hosts tested at two different localities (INECOL, Xalapa, Veracruz Mexico and Texas A\&M University, College Station, Texas, USA).

\begin{tabular}{|c|c|c|c|c|c|}
\hline Country & Host & Males & Brachypterous females & Macropterous females & Total \\
\hline México & Anastrepha ludens $\mathrm{n}=200$ & $1.53 \pm 0.06$ & 0 & $49.25 \pm 1.27$ & $50.78 \pm 1.30$ \\
\hline USA & $\begin{array}{l}\text { Anastrepha ludens } \\
\mathrm{n}=100\end{array}$ & $1.65 \pm 0.09$ & 0 & $40.3 \pm 1.78$ & $41.95 \pm 1.86$ \\
\hline México & $\begin{array}{l}\text { Trypoxylon sp. } \\
\mathrm{n}=15\end{array}$ & $12.66 \pm 0.64$ & $5.73 \pm 0.60$ & $481.8 \pm 19.83$ & $500.2 \pm 20.76$ \\
\hline México & $\begin{array}{c}\text { Sceliphron sp. } \\
\mathrm{n}=15\end{array}$ & $5.13 \pm 0.39$ & $1.86 \pm 0.36$ & $295.33 \pm 13.70$ & $302.33 \pm 14.07$ \\
\hline USA & $\begin{array}{c}\text { Sarcophaga (Neobellieria) bullata } \\
\mathrm{n}=100\end{array}$ & $3.25 \pm 0.11$ & $0.36 \pm 0.07$ & $151.36 \pm 4.37$ & $154.98 \pm 4.41$ \\
\hline
\end{tabular}


hosts as $A$. ludens, the production of brachypterous females is not observed most likely because the ovipositing female can produce a clutch size big enough to consume all the host resources.

Our study suggested a need to evaluate $M$. digitata as a natural enemy of A. ludens. In fact Anastrepha species in citrus have a low parasitism rate due to the large fruit size and a scarcity of pupal parasitoids to reduce pest population density (López et al., 1999). Furthermore, $M$. digitata can be mass produced inexpensively in high quantities, and are already available commercially for use in teaching biological concepts (Matthews et al., 2009). Experiments are required especially for testing the capacity of $M$. digitata to reach and parasitize buried $A$. ludens pupae in the soil as well as to analyze host choice preferences comparing $A$. ludens to other potential hosts since non target effects could be a critical factor given the generalist habit of this parasitoid species. Taking into account that $M$. digitata uses indirect hostassociated kairomones to locate mud dauber hosts (Cusumano et al., 2010; González et al., 2011) it would be interesting to test if such a group of semiochemicals also play a role when the parasitoid forages for A. ludens hosts.

\section{References}

ALUJA M., 1994 - Bionomics and management of Anastrepha. - Annu. Rev. Entomol. 39: 155-178.

ALUJA M., MANGAN R.L., 2008 - Fruit fly (Diptera: Tephritidae) host status determination: critical conceptual, methodological, and regulatory considerations. - Annu. Rev. Entomol. 53: 473-502.

ALUJA M., CELEDONIO-HURTADO H., LIEDO P., CABRERA M., CASTILLO F., GUILLÉN J., RIOS E., 1996 - Seasonal population fluctuations and ecological implications for management of Anastrepha fruit flies (Diptera: Tephritidae) in commercial mango orchards in Southern Mexico. - J. Econ. Entomol. 89 (3): 654-667.

ALUJA M., RULL J., PÉREZ-STAPLES D., DÍAZ-FLEISCHER F., SIVINSKI J., 2009 - Random mating among Anastrepha ludens (Diptera: Tephritidae) adults of geographically distant and ecologically distinct populations in Mexico. - Bull. Entomol. Res. 99 (2): 207-214.

BIRKE A., ALUJA M., GREANY P., BIGURRA E., PÉREZ-STAPLES D., MCDONALD R., 2006 - Long aculeus and behavior of Anastrepha ludens renders gibberellic acid ineffective as an agent to reduce Ruby Red grapefruit susceptibility to the attack of this pestiferous fruit fly in commercial citrus orchards. - J. Econ. Entomol. 99 (4): 1184-1193.

CANCINO J., RUÍZ L., SIVINSKI J., GÁLVEZ F., ALUJA M., 2009 - Rearing of five hymenopterous larval-prepupal (Braconidae, Figitidae) and three pupal (Diapriidae, Chalcidoidea, Eurytomidae) native parasitoids of the genus Anastrepha (Diptera: Tephritidae) on irradiated A. ludens larvae and pupae. - Biocontrol Sci. Technol. 19 (Suppl 1): $193-209$.

CÔNSOLI F., VINSON S.B., 2002a - Clutch size, development and wing morph differentiation of Melittobia digitata. - Entomol. Exp. Appl. 102 (2): 135-143.

CÔNSOLI F., VINSON S.B., 2002b - Larval development and feeding behavior of the wing dimorphics of Melittobia digitata Dahms (Hymenoptera: Eulophidae). - J. Hym. Res. 11 (2): 188-196.

CÔNSOLI F., VINSON S.B., 2004 - Wing morph development and reproduction of the ectoparasitoid Melittobia digitata: nutritional and hormonal effects. - Entomol. Exp. Appl. 112 (1): 47-55.

COPELAND C., MATTHEWS R.W., GONZÁLEZ J.M., ALUJA M., SIVINSKI J., 2008 - Wolbachia in two populations of Melittobia digitata Dahms (Hymenoptera: Eulophidae). - Neotrop. Entomol. 37 (6): 633-640.

CROSS E.A., STITH M.G., BAUMAN T.R., 1975 - Bionomics of the organ- pipe mud-dauber, Trypoxylon politum (Hymenoptera: Sphecoidea). - Ann. Entomol. Soc. Am. 68 (56): 901-916.

CUSUMANO A., GONZÁLEZ J.M., COLAZZA S., VINSON S.B., 2010 Behavioral responses of the parasitoid Melittobia digitata to volatiles emitted by its natural and laboratory hosts. - Entomol. Exp. Appl. 136 (3): 301-307.

DAHMS E.C., 1984 - Revision of the genus Melittobia (Chalcidoidea; Eulophidae) with the description of seven new species. - Memoirs of the Queensland Museum 21 (2): 271-336.

GONZÁLEZ J.M., ABE J., MATTHEWS R.W., 2004a - Offspring production and development in the parasitoid wasp Melittobia clavicornis (Cameron) (Hymenoptera: Eulophidae) from Japan. - Entomol. Sci. 7 (1): 15-19.

GONZÁLEZ J.M., ACOSTA E., SORMANI C., VINSON S.B., 2010 Melittobia digitata Dahms (Hymenoptera: Eulophidae) and Monodontomerus mexicanus Gahan (Hym.: Pteromalidae) on a nest of Trypoxylon (Trypargilum) mexicanum (Saussure) (Hym.: Crabronidae) collected near Xalapa, Veracruz, Mexico. - Acta Zool. Mex. 26 (1): 215-218.

GONZÁLEZ J.M., CUSUMANO A., WILLIAMS H.J., COLAZZA S., VINSON S.B., 2011 - Behavioral and chemical investigations of contact kairomones released by the mud dauber wasp Trypoxylon politum, a host of the parasitoid Melittobia digitata. - J. Chem. Ecol. 37 (6): 629-639.

GONZÁLEZ J.M., MATTHEWS R.W., 2002 - Development and sex ratio of Melittobia australica and M. digitata (Hymenoptera: Eulophidae) on Megachile rotundata (Hymenoptera: Megachilidae) and Trypoxylon politum (Hymenoptera: Sphecidae). - Great Lakes Entomologist 35 (1): 85-91.

GONZÁLEZ J.M., MATTHEWS R.W., 2005 - Courtship of the two female morphs of Melittobia digitata (Hymenoptera: Eulophidae). - Fla. Entomol. 88 (3): 258-267.

GONZÁLEZ J.M., MATTHEWS R.W., 2008 - Female and male polymorphism in two species of Melittobia parasitoid wasps (Hymenoptera: Eulophidae). - Fla. Entomol. 91 (2): 162-169.

GONZÁLEZ J.M., MATTHEWS R.W., VINSON S.B., 2008 - Distribution and host records of Melittobia (Hymenoptera: Eulophidae) from Mexico. - Revista Mexicana de Biodiversidad 79: 529-531.

GONZÁLEZ J.M., TERÁN J.B., MATTHEWS R.W., 2004b - Review of the biology of Melittobia acasta (Walter) (Hymenoptera: Eulophidae) and additions on development and sex ratio of the species. Caribbean J. Sci. 40 (1): 52-61.

HERNÁNDEZ-ORTIZ V., 1992 - El género Anastrepha Schiner en México (Diptera: Tephritidae). Taxonomía, distribución y sus plantas huéspedes. Instituto de Ecología, A.C. - Sociedad Mexicana de Entomología. Xalapa, Veracruz, México.

HODGSON P.J., SIVINSKI J., QUINTERO G., ALUJA M., 1998 - Depth of pupation and survival of fruit fly (Anastrepha spp.: Tephritidae) pupae in a range of agricultural habitats. Environ. Entomol. 27 (6): $1310-1314$.

LA SALLE J., 1993 - North American genera of Tetrastichinae (Hymenoptera: Eulophidae). - J. Natl History 28 (1): 109-236.

LÓPEZ M., ALUJA M., SIVINSKI J., 1999 - Hymenopterous larval-pupal and pupal parasitoids of Anastrepha flies (Diptera: Tephritidae) in Mexico. - Biol. Control 15 (2): 119-129.

MENA-CORREA J., SIVINSKI J., ANZURES-DADDA A., RAMÍREZROMERO R., GATES M., ALUJA M., 2010 - Consideration of Eurytoma sivinskii Gates and Grissell, a eurytomid (Hymenoptera) with unusual foraging behaviors, as a biological control agent of tephritid (Diptera) fruit flies. - Biol. Control 53 (1): 9-17.

MANGAN R.L., FRAMPTON E.R., THOMAS D.B., MORENO D.S., 1997 Application of the maximum pest limit concept to quarantine security standards for the Mexican fruit fly (Diptera: Tephritidae). - J. Econ. Entomol. 90 (6): 1433-1440. 
MATTHEWS R.W., GONZÁLEZ J.M., 2008 - The acasta conundrum: polymorphism and taxonomic confusion within the parasitoid genus Melittobia (Hymenoptera: Eulophidae). - Zootaxa 1854: 45-54.

MATTHEWS R.W., GONZÁLEZ J.M., MATTHEWS J.R., DEYRUP L.D., 2009 - Biology of the parasitoid Melittobia (Hymenoptera: Eulophidae). - Annu. Rev. Entomol. 54: 251-266.

MATTHEWS R.W., KOBALLA T.R. Jr., FLAGE L.R., PYLE E.J., 1996 WOWBugs: new life for life science. Riverview Press, Athens.

OVRUSKI S., ALUJA M., SIVINSKI J., WHARTON R., 2000 Hymenopteran parasitoids on fruit-infesting Tephritidae (Diptera) in Latin America and the southern United States: diversity, distribution, taxonomic status and their use in fruit fly biological control. - Integrated Pest Manag. Rev. 5 (2): 81-107.

PURCELL M., 1998 - Contribution of biological control to integrated pest management of tephritid fruit flies in tropics and subtropics. Integrated Pest Manag. Rev. 3 (2): 63-83.

SIEGEL S., CASTELLAN N.J. Jr, 1988 - Nonparametric statistics for behavioral sciences. McGraw-Hill, New York.

SIMBERLOFF D., STILING P., 1996 - How risky is biological control? Ecology 77 (7): 1965-1974.
SIVINSKI J., 1991 - The influence of host fruit morphology on parasitization rates in the Caribbean fruit fly, Anastrepha suspensa. Entomophaga 36 (3): 447-454.

STATSOFT, 2001 - Statistica per Windows, User's Manual. StatSoft Italia, Vigonza, Padova, Italy.

TANNER D.A., GONZÁLEZ J.M., MATTHEWS R.W., VINSON S.B., PITTS J., 2011 - Evolution of the courtship display of Melittobia (Hymenoptera: Eulophidae). - Mol. Phylogenet. Evol. 60 (2): 219227.

THOMAS D.B., 2003 - Reproductive phenology of the Mexican fruit fly, Anastrepha ludens (Loew) (Diptera: Tephritidae) in the Sierra Madre Oriental, Northern Mexico. - Neotrop. Entomol. 32 (3): 385397.

THOMAS D.B., EPSKY N.D., SERRA C.A., HALL D.G., KENDRA P.E., HEATH R.R., 2008 - Ammonia formulations and capture of Anastrepha fruit flies (Diptera: Tephritidae). - J. Entomol. Sci. 43 (1): 76-85.

ZAR J.H., 1999 - Biostatistical analysis. Prentice Hall, Upper Saddle River, New Jersey. 